\title{
Erratum to: A representation of a compressed de Bruijn graph for pan-genome analysis that enables search
}

Timo Beller and Enno Ohlebusch*

\section{Erratum to: Algorithms Mol Biol (2016) 11:20 DOI 10.1186/s13015-016-0083-7}

After publication of the original article [1], the authors noticed errors in Algorithm 2 and the caption of Table 4. In Algorithm 2, the term " $\operatorname{rank}_{1}\left(\mathrm{~B}_{1}, \mathrm{i}-1\right)+1$ " should be included on line 28 and not line 29 . In addition, in the caption of Table 4, the word "BV ${ }_{r}$ " should be replaced by " $\mathrm{B}_{\mathrm{r}}$ " and the word " $\mathrm{BV} \mathrm{V}_{1}$ " should be replaced by " $\mathrm{B}_{1}$ ". The correct versions of Algorithm 2 and Table 4 are included in this erratum.
Table 4 Breakdown of the space usage of the variants of Algorithm A4

\begin{tabular}{|c|c|c|c|c|}
\hline Algorithm & Part & 62 E.coli & $7 \times$ Chr1 & $7 \times \mathrm{HG}$ \\
\hline A4 & wt-bwt & $0.42(23.83 \%)$ & $0.44(36.23 \%)$ & $0.43(22.68 \%)$ \\
\hline A4 & Nodes & 0.10 (5.94\%) & $0.03(2.61 \%)$ & $0.04(2.02 \%)$ \\
\hline A4 & $B_{r}$ & 0.16 (8.93\%) & $0.16(12.86 \%)$ & $0.16(8.25 \%)$ \\
\hline A4 & $B_{l}$ & 0.14 (8.04\%) & $0.14(11.57 \%)$ & $0.14(7.42 \%)$ \\
\hline A4 & wt-doc & $0.93(53.26 \%)$ & $0.45(36.73 \%)$ & $1.13(59.63 \%)$ \\
\hline A 4 compr 1 & wt-bwt & $0.42(28.57 \%)$ & $0.44(47.83 \%)$ & $0.43(26.85 \%)$ \\
\hline A 4 compr 1 & Nodes & $0.10(7.12 \%)$ & $0.03(3.44 \%)$ & 0.04 (2.39\%) \\
\hline A 4 compr 1 & $B_{r}$ & $0.00(0.23 \%)$ & $0.00(0.12 \%)$ & $0.00(0.09 \%)$ \\
\hline A 4 compr 1 & $B_{l}$ & $0.00(0.23 \%)$ & $0.00(0.12 \%)$ & $0.00(0.08 \%)$ \\
\hline A 4 compr 1 & wt-doc & $0.93(63.85 \%)$ & $0.45(48.49 \%)$ & $1.13(70.59 \%)$ \\
\hline A 4 compr 2 & wt-bwt & $0.16(13.03 \%)$ & $0.22(31.01 \%)$ & $0.22(15.62 \%)$ \\
\hline A 4 compr 2 & Nodes & 0.10 (8.67\%) & $0.03(4.55 \%)$ & $0.04(2.76 \%)$ \\
\hline A 4 compr 2 & $B_{r}$ & $0.00(0.28 \%)$ & $0.00(0.16 \%)$ & $0.00(0.10 \%)$ \\
\hline A 4 compr 2 & $B_{l}$ & $0.00(0.28 \%)$ & $0.00(0.16 \%)$ & $0.00(0.10 \%)$ \\
\hline A 4 compr 2 & wt-doc & $0.93(77.74 \%)$ & $0.45(64.11 \%)$ & $1.13(81.42 \%)$ \\
\hline
\end{tabular}

The first column shows the algorithm used in the experiment (the $k$-mer size is 50). The second column specifies the different data structures used: wt-bwt stands for the wavelet tree of the BWT (including rank and select support), nodes stands for the array of nodes (the implicit graph representation), $B_{\mathrm{r}}$ and $B_{l}$ are the bit vectors described in "Computation of right-maximal $k$-mers and node identifiers" section (including rank support), and wt-doc stands for the wavelet tree of the document array. The remaining columns show the memory usage in bytes per base pair and, in parentheses, their percentage

\footnotetext{
${ }^{*}$ Correspondence: Enno.Ohlebusch@uni-ulm.de Institute of Theoretical Computer Science, Ulm University, James-Franck-Ring O27/537, 89069 Ulm, Germany
} 


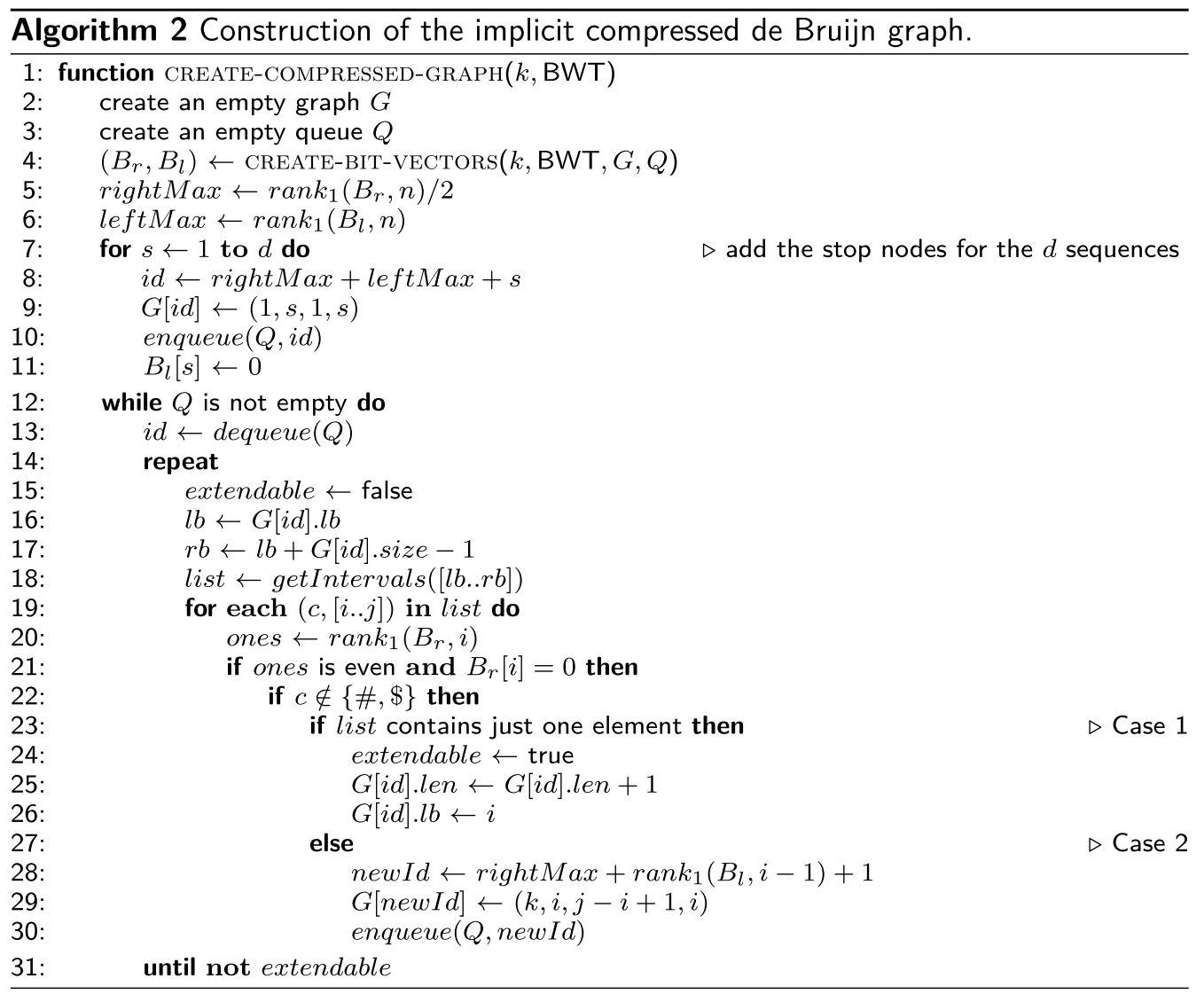

The online version of the original article can be found under doi:10.1186/s13015-016-0083-7.

Received: 9 November 2016 Accepted: 9 November 2016

Published online: 28 November 2016

\section{Reference}

1. Beller T, Ohlebusch E. A representation of a compressed de Bruijn graph for pan-genome analysis that enables search. Algorithms Mol Biol. 2016;11:20. doi:10.1186/s13015-016-0083-7.

Submit your next manuscript to BioMed Central and we will help you at every step:

- We accept pre-submission inquiries

- Our selector tool helps you to find the most relevant journal

- We provide round the clock customer support

- Convenient online submission

- Thorough peer review

- Inclusion in PubMed and all major indexing services

- Maximum visibility for your research

Submit your manuscript at www.biomedcentral com/submit 